\title{
Microparticles in kidney diseases: focus on kidney transplantation
}

\author{
Fateme Shamekhi Amiri
}

\begin{abstract}
Background: Microparticles are small $(0.1-1 \mu \mathrm{m})$, extracellular vesicles that are used as diagnostic and prognostics markers of kidney diseases and kidney transplantation. They contain cytoplasm and surface markers of their cells of origin. The aim of this review is to describe the functional capabilities of microparticles in kidney diseases with focus on kidney transplantion.

Main body: Microparticles represent a novel and potentially important method of cell-cell communication, regulating a number of physiological/pathophysiological processes. Increased levels of circulating microparticles, mainly originating from platelets and endothelial cells, have been proposed as causing vascular and endothelial dysfunction in renal diseases. Furthermore, higher levels of endothelial MPs that are observed in hemodialyzed patients reached to normal values after graft. Circulating microparticles have been used in kidney rejection and transplant vasculopathy. The genetic content of circulating microvesicles may have great use for diagnostic and prognostic purposes after organ transplantation.
\end{abstract}

Conclusion: Microparticles may be a novel marker for creation and diagnosis of different diseases in kidney diseases especially kidney transplantion that imply for further research.

Keywords: Cardiovascular disease, Circulating endothelial cells, Kidney diseases, Kidney transplantion, Microparticles

\section{Background}

Intercellular communication is vital for the regulation and coordination of many different processes within multicellular organisms. Extracellular membrane-bound vesicles are emerging as a novel and significant mechanism of cell signaling and communication [1]. Extracellular vesicles are a heteregenous population of particles released from various cell types into the extracellular spaces under both normal and stressed condition. Research on extracellular vesicles (EVs) is not only focused on their potential role as source of biomarkers but also as new therapeutic tools. In the context of acute kidney injury (AKI), only a few studies have tested different sources of EVs for their therapeutic potential. The microRNA (miRNA) content of these vesicles seems to have a positive effect in tubular cells, reducing apoptosis and promoting cell proliferation. Ischemia-reperfusion is characterized by the overexpression of the adhesion molecule of monocyte chemoattractant

Correspondence: fa.shamekhi@gmail.com

Division of Nephrology, Imam Khomeini Hospital, Faculty of Medicine, Tehran University of Medical Sciences, Tehran, Iran
protein-1(MCP-1). During this process, transcriptional repressor activating transcription factor 3 (ATF3), which has an anti-apoptotic and anti-inflammatory effect, is induced.

This paper has written based on searching PubMed and Google Scholar to identify potentially relevant articles or abstracts. The mentioned search included the following search terms: Microparticles, microparticles in renal transplantation, and microparticles in kidney transplantation. Search terms were used both discretely and combined with each other using the Boolean operator AND. The author reviewed the bibliographies of all selected articles to identify additional relevant studies. The search retrieved 308 articles; after evaluating the abstracts, 184 articles were excluded. The manuscripts of the remaining 124 articles were completely read and, of these, 109 were excluded due to unrelated subject to kidney transplantation and non-original investigation. Finally, 15 original studies were included in this review (Fig. 1). The aim of this review is to describe the functional capabilities of microparticles in kidney transplantation. In this regard, at first, microparticles and the methods of measuring of these biomarkers and 


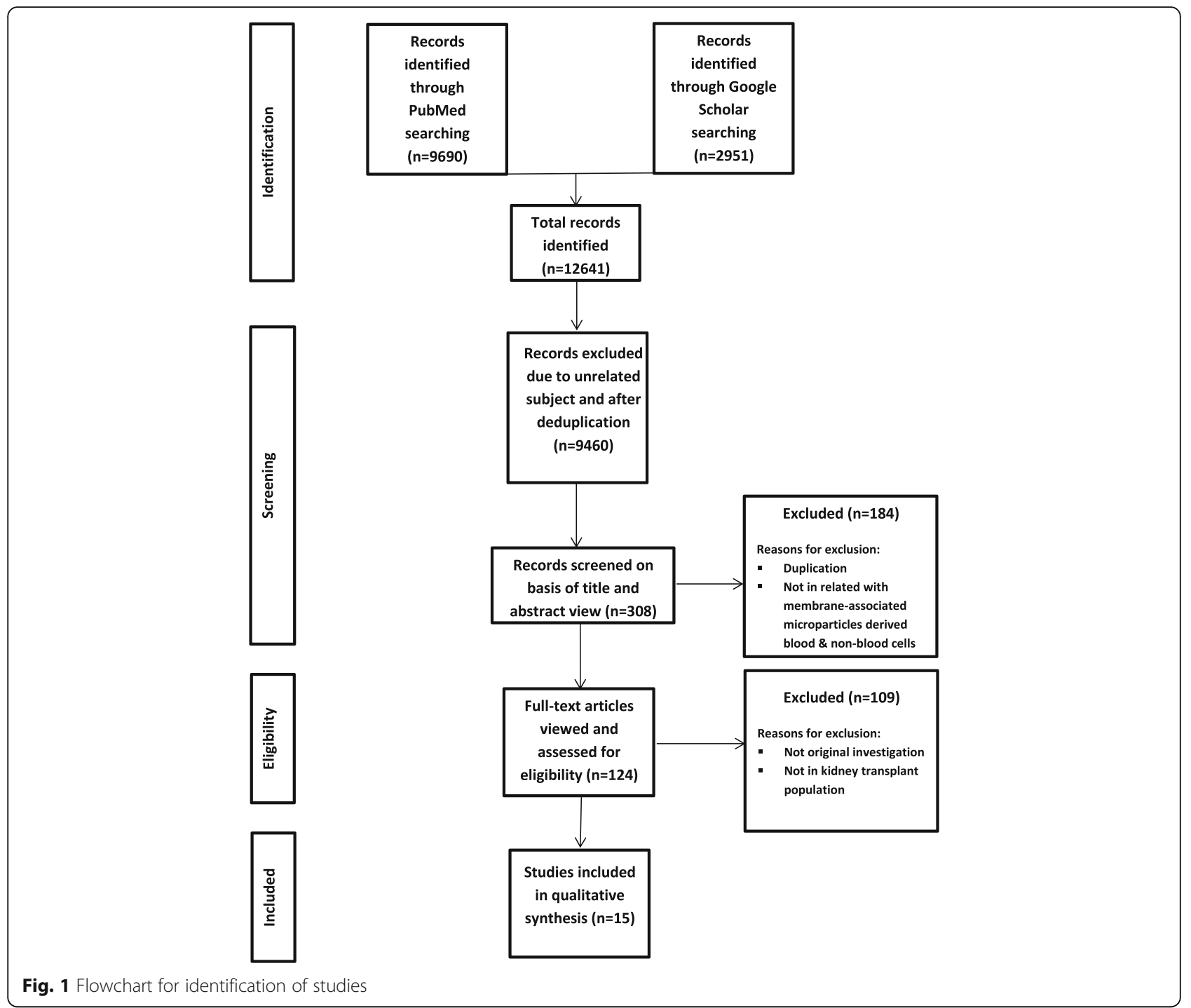

then pathophysiological processes of kidney diseases relating with microparticles are discussed, briefly. Finally, the discussion is focused on deleterious effects that are caused by microparticles in kidney transplantation.

\section{Microparticles}

Extracellular vesicles are divided into three categories-exosomes, apoptotic bodies, and microparticles or microvesicles-on the basis of their size, content, and mechanism of formation [2]. Less common terms for extracellular vesicles, such as exosome-like vesicles (implying 2050-nm particles similar to exososomes but lacking lipidrich domains) and membrane particles (which refer to 50-100 nm) membrane fragments enriched in CD133/ prominin-1, are more poorly defined and infrequently used [3]. Among the various types of extracellular vesicles formed, membrane microparticles (also referred to as ectosomes or more broadly, microvesicles) are emerging as both indices of vascular injury and as circulating biologically active entities. Cells in human blood generate a variety of membrane microparticles (MPs), and determination of the cellular origin of MP relies on the expression of specific antigens. First identified by wolf in 1967, MPs (shedding vesicles) are cell plasma membrane-derived small vesicles which are $0.1-1 \mu \mathrm{m}$ in diameter. MPs are generated from a variety of different vascular cell types, including endothelial cells, monocytes, platelets, red blood cells, and granulocytes. Early studies on MPs focused on platelets because these cells readily generated MPs on activation. Indeed, the original term for MPs was "platelet dust" and platelets are the major source of MPs in the blood of healthy individuals [4]. When stimulated by various environmental factors including serine proteases, inflammatory cytokines, growth factors, and 
stress inducers, nearly all kinds of mammalian cells can generate MPs [5]. Most studies have shown that microparticles are heterogeneous and vary in phospholipids, surface antigens, and protein contents. MP release is a controlled process triggered by various stimuli including proapoptotic stimulation, shear stress, agonists, or damage [6]. By general consensus, MPs are small in size, expose the anionic phospholipid (PL) phosphatidylserine (PS) on the outer leaflet of their membrane, and bear surface membrane antigens reflecting their cell of origin [7]. Believed to be formed by all cell types, MP formation has been observed in cells of the vasculature (endothelial cells, platelets, leukocytes and vascular smooth muscle cells, erythrocytes) and podocytes, as well as cancer and progenitor cell populations (Fig. 2). MPs may be distinguished from other common extracellular vesicles (such as exososomes or apoptotic bodies) on the basis of size, mechanism of formation, and content. Exososomes are smaller (approximately 40-100 $\mathrm{nm}$ ) than MPs and are formed through a multi-step process [8]. Apoptotic bodies are much larger than exosomes or MPs with a size of $1-5 \mu \mathrm{m}$. They are formed exclusively during the late stages of apoptosis during cell shrinkage/collapse and after externalization of phosphatidylserine, increases in membrane permeability, and karyorrhexis (nuclear fragmentation).

\section{MPs composition, formation, and release}

In multicellular organisms, homeostasis results from a subtle balance between cell proliferation and degenerescence. Cells differentiate, expand, fulfill particular functions, then undergo programmed death, and are finally cleared by phagocytosis. At each stage of its life, the cell is subjected to a variety of stimulations leading to the

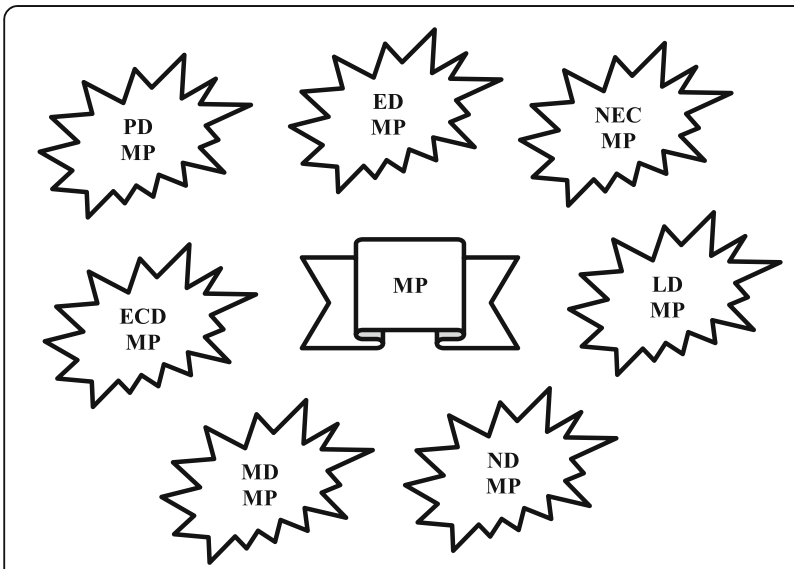

Fig. 2 Classification of microparticles. ECD MP endothelial cell-derived microparicles, ED erythrocyte-derived, LD lymphocyte-derived, $M D$ monocyte-derived, NECD nonendothelial cell-derived, ND neutrophil-derived, $P D$ platelet-derived release of submicron fragments from the plasma membrane, usually termed microparticles or microvesicles. MPs hijack membrane constituents and cytoplasmic content and survive the cell. Membrane microparticles are shed from the plasma membrane of stimulated cells. They harbor membrane and carry cytoplasmic proteins as well as bioactive lipids implicated in a variety of fundamental processes. This representation does not intend to be exhaustive with respect to the different hijacked components [9]. MPs contain a wide range of biomolecules: proteins (signal proteins and receptors, cytoskeleton, and effector proteins), lipids, and nucleic acids (e.g., microRNA, mRNA, and even DNA). MP surface protein content may be different from that of the plasma. Membrane of the original cell, as the incorporation of protein molecules into MPs, can be selective and modulated by agonist activators and/or microenvironments of the parental cells. Depending on the stimulus, the protein content of MPs derived from the same cell lineage can vary [10]. Although the precise molecular determinants of MP are unknown, mechanisms of plasma membrane remodeling cause MP formation including cytoskeletal reorganization and externalization of phosphatidylserine (PS). Furthermore, lipid-rich microdomains including lipid rafts and caveolae have also been implicated in the formation of endothelial, monocyte, and platelet MPs.

In PS externalization (loss of membrane phospholipid asymmetry), under resting conditions, phospholipids are asymmetrically distributed in the membrane of eukaryotic cells. The outer leaflet is enriched in phosphatidylcholine and sphingomyelin, whereas the inner leaflet contains the aminophospholipids PS and phosphatidylethanolamine. The appearance of PS or phosphatidylethanolamine on the outer leaflet results in a back-transportation to the inner leaflet by an aminophospholipid translocase with "flippase" activity that maintains the normal resting phospholipid distribution. Because uncatalyzed transbilayer transport is slow, lipid asymmetry is stable in quiescent cells. This distribution is controlled by three proteins, namely a flippase (governing their inward translocation), a floppase (governing their outward translocation), and a lipid scramblase. The phospholipid transient mass imbalance between the two leaflets due to membrane randomization and the proteolysis of the cytoskeleton promoted by calcium-activated calpains promote the shedding of MPs. Importantly, PS exposure appears to be a nearly universal feature of cells undergoing activation or apoptosis and a common underlying feature of MP release by these cells [11].

In cytoskeletal reorganization, cytoskeleton integrity is believed to participate in the maintenance of membrane asymmetry and cell shape, its reorganization could 
therefore favor membrane budding in stimulated cells. Unlike agonist-induced MP generation, this mechanism does not require either $\mathrm{Ca}^{2+}$ elevation or the activity of calpain, a $\mathrm{Ca}^{2+}$-dependent thiol protease known to modify platelet cytoskeleton and some signal transduction enzymes. Although baseline calpain activity seems insufficient to degrade cytoskeleton components, agonist-induced $\mathrm{Ca}^{2+}$ influx is necessary to reach $\mathrm{Ca}^{2+}$ concentrations sufficiently high to induce maximum protease activity. Calpains have been known for more than a decade to play a crucial role in platelet shedding. Caspases are cytoplasm proteases from the apoptotic cascade involved in the reorganization of the cytoskeleton, possibly related to either membrane remodeling or cell differentiation. Caspases or calpain is responsible for the proteolytic cleavage of prominent cytoskeletal proteins such as filamin-1 (a marker of megakaryocyte derived MPs), gelosin, talin, and myosin. In the Jurkat $\mathrm{T}$ lymphocyte cell line, caspase- 3 mediates the cleavage of Rho-associated coiled-coil containing protein kinases (ROCK I), a Rho-kinase acting by myosin light chain phosphorylation that induces cell membrane contraction and MP release during apoptosis. ROCK-I, the Rho-kinase isoform that is activated by caspase-3, was not modulated by thrombin. A group of genes are linked to the cytoskeleton reorganization and involved in MP release from endothelial cells. Of these, the Rho-kinase ROCK-II activated by caspase- 2 showed a high transcription rate [12-14].

The current knowledge on MP formation derives mainly from experiments on isolated or cultured cells showing that both cell activation and cell apoptosis can lead to MP release. However, in vivo mechanisms involved in MP formation and shedding remain mostly unknown. MPs are released from cell membranes by triggers such as cytokines, thrombin, endotoxins, hypoxia, and shear stress, capable of inducing activation or apoptosis. Phosphatidylserine exposure is not always followed by the release of MPs, which may be regulated by the level of intracellular calcium. Moreover, MP shedding necessitates modifications in cell structural architecture involving disruption of cytoskeleton protein organization. In platelets, MP release seems to be controlled by calcium-dependent activation of calpain, a cytosolic cysteine protease involved in rearrangement of cytoskeleton proteins and protein cleavage to activate various receptors and proenzymes. Platelets release MPs after activation by thrombin, adenosine diphosphate (ADP) plus collagen, the complement complex C5b-9, the calcium ionophore A23187, and by high shear stress. Endothelial cells, monocytes, vascular smooth muscle cells, and hepatocytes can also release MPs after activation by bacterial lipopolysaccharides, inflammatory cytokines including tumor necrosis factor or interleukin-1, the complement complex C5b-9, aggregated low density lipoproteins, or reactive oxygen species. Increase in intracellular calcium, most likely at the site of membrane vesicle formation, seems to be a critical step for MP release, but the role of cytoskeleton is not yet fully elucidated. In apoptosis-induced MP release, apoptosis is characterized by cell contraction and DNA fragmentation. Blebbing of the cellular membrane occurs rapidly after cells enter the apoptotic process. Bleb formation depends on actin cytoskeleton and actin-myosin contraction, which is regulated by caspase 3-induced Rhokinase I activation. Rho-kinase activation is required for relocalization of DNA fragments from the nuclear region to membrane blebs, suggesting that MPs from apoptotic cells may contain nuclear material. Interestingly, statins inhibit MP release from cultured endothelial cells by altering the Rho-kinase pathway [15]. Distler et al. in a study determined the effects of microparticles released from Jurkat T cells on RAW 264.7 cells for elucidating the interactions of microparticles with macrophages. Microparticles were isolated by differential centrifugation, using FACS analysis with annexin V and cell surface markers for identification. Various inducers of apoptosis increased the release of microparticles from Jurkat cells up to 5-fold. Furthermore, microparticles stimulated the release of microparticles from macrophages. These findings indicate that microparticles can induce macrophages to undergo apoptosis [16].

\section{Stimuli for MP production}

Membrane vesiculation occurs in vivo as a result of various stimuli and signaling mechanisms [17]. A number of cell activation and apoptosis triggers which induce MP formation have been identified including chemical stimuli such as cytokines, thrombin, and endotoxin or physical stimuli such as shear stress or hypoxia. In particular, high shear stress can initiate both platelet aggregation and shedding of procoagulant-containing platelet-derived microparticles (PDMPs) [18]. Higher shear stress-induced activation of platelets and the addition of platelet microparticles (PMPs) may also enhance the expression of cell adhesion of molecules and the production of the cytokines in the human monocytic leukemia cell line (THP-1) and ECs. Platelets release MPs after activation by thrombin, ADP plus collagen, the complement complex C5b-9, the calcium ionophore A23187, and by high shear stress. Endothelial cells, monocytes, vascular smooth muscle cells, and hepatocytes can also release MPs after activation by bacterial lipopolysaccharides, inflammatory cytokines including tumor necrosis factor or interleukin-1, the complement complex C5b-9, aggregated low density lipoproteins, or reactive oxygen species [19] (Fig. 3). 


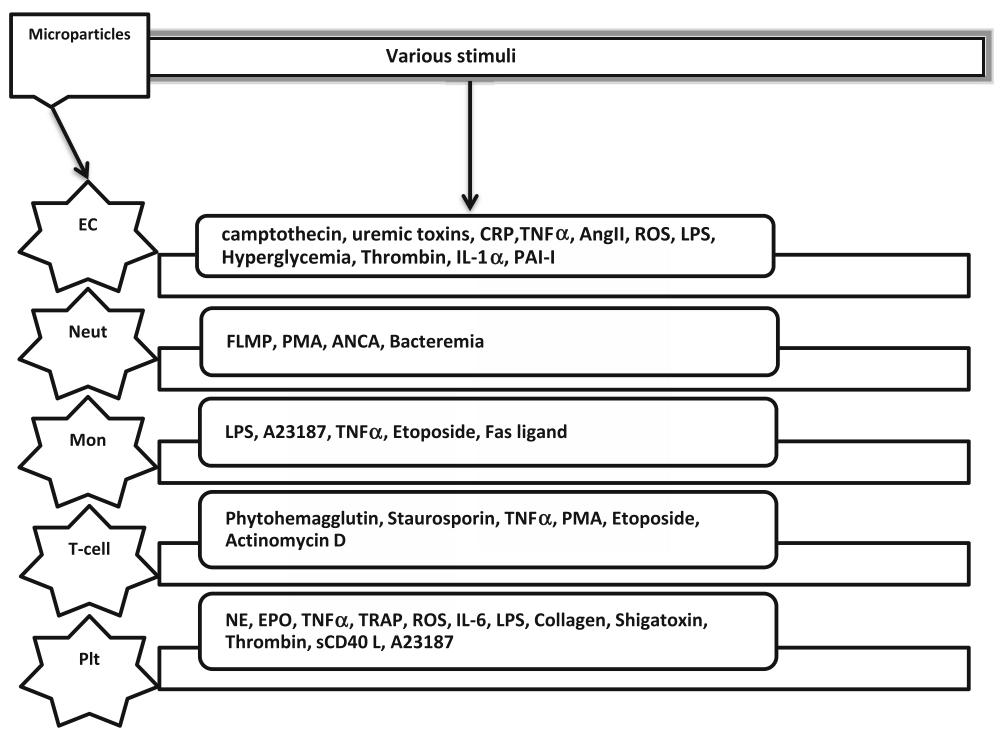

Fig. 3 Stimuli for microparticle production. EC MPs endothelial cell microparticles, Mon monocyte MPs, Neut neutrophil MPs, Plt MPs Platelet MPs

\section{MP elimination}

Cells become susceptible to complement-induced lysis when they lose key complement inhibitors such as CD46, CD55, and CD59. These inhibitors are sorted to microparticles and exosomes, most likely to prevent complement deposition and lysis of these vesicles, thereby increasing their chance of survival in the extracellular environment. Although exosomes can be internalized via phagocytosis by binding to the PS receptor T cell immunoglobulin and mucin-domain containing molecule (TIM-4), the extent to which exosomes and microvesicles expose PS in vivo remains unclear. Phagocytosis of PS-exposing cells and microparticles may be mediated by lactadherin, because lactadherin knockout mice have an increased concentration of (platelet-derived) microparticles, and splenic macrophages from these mice show a decreased capacity to phagocytose these microparticles, resulting in a hypercoagulable state. In most other studies, however, relatively fast (10-30 min) but also much slower (5-6 h) half-life times of vesicle disappearance were reported. The clearance of vesicles will undoubtedly depend on the organism studied, the clinical conditions, and whether artificial phospholipid vesicles or cell-derived vesicles were studied [3]. Clearance of MPs occurs through several main mechanisms. The major one is degradation due to the action of phospholipases and proteases. Other potential routes of MP clearance include opsonization with subsequent phagocytosis, uptake of MPs from the circulation by liver Kupffer cells in a PS-dependent manner, phagocytosis of MPs by splenocytes, and uptake of MPs by the lung macrophages $[13,20]$. Jurkat $\mathrm{T}$ cell-derived apoptotic MPs have been shown to be engulfed by macrophages in vitro [16]. Moreover, study by Litvack et al. revealed that natural IgM is an important antibody to clear microbes and other bioparticles, and that shape is critical to particle uptake by macrophages as such there is an inverse relationship between IgM-mediated clearance by macrophages and the particle size [21].

\section{MP measurement}

The majority of studies investigate isolated-MPs from plasma samples, which typically contain endothelial-, leukocyte-, platelet- and erythrocyte-derived MPs. Under pathological conditions, MPs derived from non-circulating cells, for example, vascular smooth muscle cells or fibroblasts, might also be detectable, although there is a dearth of knowledge in this area. The main methods of MP detection include flow cytometry, enzyme-linked immunoassays, and functional coagulative assays. A recently developed new method for the detection of plasma MPs using a fluorescence-based antibody array system can rapidly identify the cell origin of MPs. MP counting, as currently performed by flow cytometry, certainly needs to be standardized [22]. Both methods of MP analysis rely on antibody detection of specific cellular markers and annexin $\mathrm{V}$ binding of phosphatidylserine. In addition to the above techniques, the antigenic characteristics and the membrane composition of blood MPs have been studied using electron microscopy, confocal microscopy, high performance liquid chromatography, capillary electrophoresis, and mass spectrometry with varying degrees of success [7]. Other methods include western blotting, flow imaging cytometry, and nanoparticle tracking analysis $[1,7,9,23]$ 
(Table 1). Additionally, MPs of varying origins may be found in urine [24-29], bronchoalveolar lavage fluid [30], sputum [31], synovial fluid [32], ascites [33], and saliva [34]. There is presently no reliable approach for obtaining and/or characterizing MPs from tissue samples, and knowledge of MP biology in tissue is lacking.

\section{Pathophysiological processes induced by MPs in kidney diseases}

Increased levels of circulating microparticles, mainly originating from platelets and endothelial cells, have been proposed as causing vascular and endothelial dysfunction in renal diseases. Neutrophil MPs carry a large set of cell adhesion molecules and proteases such as proteinase 3 or elastase. During chronic renal failure progression, pro-inflammatory cytokines are increased and inflammation could explain in part the decline of renal function because of accerelated atherosclerosis. During acute vascular lesions such as wegener granulomatosis or micro-polyangitis, PMP and NMP are increased. Elevation of endothelial microparticles (EMP) has also been reported in antiphospholipid syndrome and uremic patients in the absence of a clinical history of vascular disease. High platelet MP levels are observed in microangiopathies and chronic renal failure patients (pre-dialyzed, under hemodialysis, and under continuous ambulatory peritoneal dialysis). In patients with ESRD, platelet, erythrocyte, and endothelial MPs are increased. EMP levels correlate with a loss of flow-mediated dilatation and increased aortic pulse wave velocity, suggesting that they are highly associated with arterial and endothelial dysfunction. A dramatic increase in PMP is observed at the end of dialysis session. This is probably due to membrane-induced complement activation and biological effects of extracorporeal dialyzers. Endotoxins of the dialysate fluid are another cause of MP release. MPs behave as effectors that play a deleterious role in renal diseases. They also represent novel biomarker that are useful to appreciate cardiovascular risk associated with chronic kidney disease and sometimes disease activity. In the following, pathophysiological processes induced by MPs in different renal diseases are discussed here.

\section{MP in intercellular communication}

There are many known ways in which cells communicate and exchange information. Cytokines, interleukins, growth factors, chemokines, and additional small molecules provide one mechanism for cell-cell interaction. Furthermore, via specialized adhesion molecules and nanotubules, cells are capable of connecting and exchanging information. Recently, the armamentarium was extended to MP which was identified as a valuable transport and information tool. At present, there is evidence that MPs use various mechanisms to transfer information. First, MPs function as signaling molecule; second, they are enabled to transfer entire receptors; third, MPs shift mRNA and proteins, and fourth, they are even capable of transporting whole cell organelles [35]. MPs may stimulate target cells directly by surface ligands. They are equipped with different signaling proteins and lipids on their surface. MPs are carrying

Table 1 Different methods for MPs measurement

\begin{tabular}{|c|c|c|c|}
\hline Assay & Method & Advantages & Disadvantages \\
\hline $\begin{array}{l}\text { Flow cytometry } \\
\text { (fluorescence- } \\
\text { activated cell sorting) } \\
\checkmark \text { MP counting }\end{array}$ & $\begin{array}{l}\text { - Utilization of fluorescence probes } \\
\text { and light-scattering properties } \\
\text { - MPs in suspension }\end{array}$ & $\begin{array}{l}\text { - Available to most research facilities } \\
\text { - Rapid } \\
\text { - Multiple antigens may be analyzed } \\
\text { in a single sample } \\
\text { - MPs analyzed on an individual basis } \\
\text { - The gold standard of human } \\
\text { cell-derived MPs }\end{array}$ & $\begin{array}{l}\text { - Antibody binding might not occur } \\
\text { attributable to the small fraction of } \\
\text { surface antigens available } \\
\text { - Size limitations and not able to detect } \\
\text { microvesicles with diameters less than } \\
300-400 \mathrm{~nm}\end{array}$ \\
\hline - Immunoassays & $\begin{array}{l}\text { ELISA-based MP capture assays by } \\
\text { annexin V as a means of capturing } \\
\text { phospholipids or antibodies to } \\
\text { specific blood MP membrane antigens } \\
\text { or antibodies to nonspecific } \\
\text { antigens (detection antibody) }\end{array}$ & $\begin{array}{l}\text { - Available at most research } \\
\text { institutions } \\
\text { - Alternative to flow cytometry } \\
\text { approach } \\
\text { - Less costly than flow cytometry } \\
\text { - Not restricted by size }\end{array}$ & $\begin{array}{l}\text { - Analysis done in batches } \\
\text { - No size determination possible } \\
\text { - Quantifies based on a single antigen }\end{array}$ \\
\hline - Functional assays & $\begin{array}{l}\text { - Procoagulant or prothrombinase } \\
\text { activity }\end{array}$ & $\begin{array}{l}\text { - Available at most research } \\
\text { institutions } \\
\text { - Provides an indication of biological } \\
\text { activity }\end{array}$ & $\begin{array}{l}\text { - The inability to quantitate the MPs } \\
\text { - Analysis done in batches, no size } \\
\text { determination possible, measures } \\
\text { procoagulant activity-not specific } \\
\text { MP detection }\end{array}$ \\
\hline $\begin{array}{l}\text { Atomic force } \\
\text { microscopy }\end{array}$ & $\begin{array}{l}\text { - Scanning of MPs utilizing specialized } \\
\text { microscope }\end{array}$ & $\begin{array}{l}\text { - MP size detection very accurate } \\
\text { - Allows for 3D structure of MP } \\
\text { - Quantitation of MPs }\end{array}$ & $\begin{array}{l}\text { - Allows for very accurate sizing of MPs } \\
\text { - Allows for 3D view of MP structure } \\
\text { - May be used for quantification }\end{array}$ \\
\hline - Nanoparticle tracking & $\begin{array}{l}\text { - Light-scattering properties of MPs } \\
\text { detected, video capture of MP motion }\end{array}$ & $\begin{array}{l}\text { - MP size detection, quantitation } \\
\text { of MPs }\end{array}$ & $\begin{array}{l}\text { - Technology not readily available, } \\
\text { long analysis times, costly }\end{array}$ \\
\hline
\end{tabular}


certain proteins like hedgehog proteins stemming from lymphocytes. They are also able to direct the differentiation of early hematopoietic cells towards a megakaryocytic differentiation. Platelet-derived MPs exert different surface molecules allowing attachment on endothelial cells. Proteins like CD41 ( $\alpha \mathrm{II} / \beta \mathrm{III}-$ integrins) and CD62P (P-selectin) as well as bioactive lipids like arachidonic acid and sphingosine-1-phosphate are involved in these various biological processes mediated by platelet-derived MP. It has been reported that MPs activate endothelial cells, polymorphonuclear leukocytes, and monocytes. Additionally, they may also induce apoptosis in leukocytes and promote secretion of cytokines and tissue factor expression in endothelial cells. MP represents a novel mechanism of intercellular communication mediating inflammation, immunity, and blood coagulation. Their effect on target cells was long accredited to their specific lipid composition, as well as to intravesicular chemokines. However, recent data indicate that MP can also affect protein expression of their target cells by delivering RNAs [36].

A prospective study by Bitzer et al. evaluated the protective effect to miR-126 and miR-296, which are detected in the microvesicles by real-time polymerase chain reaction (RT-PCR). MiR-126 and many of its targets are highly expressed in endothelial cells, and both miR-126 and miR-296 have been implicated in angiogenesis [37]. There are several potential ways for microparticles to interact with target cells: binding to the cell surface, fusion with the plasma membrane, and endocytic uptake and recycling to the membrane. In the immunoelectron microscopy of cell surface CD81, researchers observed that endocytosed gold particles were occasionally associated with small vesicles. This indicates endocytic uptake of CD81-positive microparticles and potential recycling to the membrane of target cells. It also shows that donor cells themselves are not resistant to binding and uptake of CD81-positive vesicles. CD81 on microparticles might therefore affect cells in an autocrine and paracrine way [38].

\section{MP in blood coagulation and angiogenesis}

With respect to activated platelets, circulating MPs provide an additional procoagulant phospholipid surface for the assembly of the characteristic enzyme complexes of the blood coagulation cascade. Their catalytic properties rely on a procoagulant anionic aminophospholipid, PhtdSer, translocated to the exoplasmic leaflet after membrane remodeling. Once accessible to circulating blood factors, PhtdSer enables local concentrations necessary to achieve the kinetics requisites for optimal thrombin generation and efficient hemostasis. Indeed, shielding PhtdSer-rich surfaces decreases the catalytic efficiency of both tenase and prothrombinase complexes by 200 - and 1000-fold respectively. Additionally, PhtdSer considerably enhances the procoagulant activity of tissue factor (TF), the main cellular initiator of blood coagulation. Apoptosis and vascular cell activation are main contributors to the release of procoagulant microparticles (MPs), deleterious partners in atherothrombosis. Elevated levels of circulating platelet, monocyte, or endothelial-derived MPs are associated with most of the cardiovascular risk factors and appear indicative of poor clinical outcome. In addition to being a valuable hallmark of vascular cell damage, MPs are at the crossroad of atherothrombosis processes by exerting direct effects on vascular or blood cells. Under pathological circumstances, circulating MPs would support cellular cross-talk leading to vascular inflammation and tissue remodeling, endothelial dysfunction, leukocyte adhesion, and stimulation. Exposed membrane phosphatidylserine and functional TF are two procoagulant entities conveyed by circulating MPs. At sites of vascular injury, Pselectin exposure by activated endothelial cells or platelets leads to the rapid recruitment of MPs bearing the P-selectin glycoprotein ligand-1 and blood-borne TF, thereby triggering coagulation. Within the atherosclerotic plaque, sequestered MPs constitute the main reservoir of TF activity, promoting coagulation after plaque erosion or rupture. Lesion-bound MPs, eventually harboring proteolytic and angiogenic effectors, are additional actors in plaque vulnerability [8]. Among the non-cell-bound TF present in blood, a variant form that results from alternative splicing of the primary RNA transcript was identified: alternatively spliced TF (asTF). asTF is soluble, circulates in plasma, and is biologically active. During thrombus formation, platelet deposition may separate catalytic enzyme complexes from circulating blood. Binding of asTF as well as TF-bearing monocyte-derived MPs to platelets provides a rationale for thrombus formation and growing [12, 39]. Elevated numbers of MPs have been reported in a variety of diseases, including patients with acute coronary syndromes, cancer, antiphospholipid antibody syndrome, sickle cell disease, sepsis, and diabetes. Although all MPs are procoagulant, those with the highest procoagulant activity are MPs derived from activated monocytes because of the presence of tissue factor. This transmembrane receptor is a potent activator of the coagulation cascade [4]. The procoagulant activity of MPs can be quantified using the thrombin generation test. In this system, MPs supply the procoagulant surface, while TF and plasma provide the necessary coagulation factors. By adding calcium ions, coagulation factors bind to MPs to initiate coagulation. In this assay, the generation of thrombin is dependent on the presence and activity of MPs, and in their absence, no coagulation would occur 
[18]. MPs were shown to induce angiogenesis, in vitro and in vivo.

The controversial effects and the importance of direct stimulation of endothelial cells by MP was shown using MP generated from activated T cells harboring the morphogen sonic hedgehog. These MPs induced an inhibition of endothelial cell migration and proliferation. However, these same MP increased capillary-like formation through the upregulation of proteins such as intercellular adhesion molecule-1 and Rho $\mathrm{A}$ and the activation of focal adhesion kinase (FAK) and other proangiogenic factors, mainly vascular endothelial growth factor (VEGF), via the activation of the sonic hedgehog pathway [40]. A direct consequence of PS expression on EMP is that PS can bind to coagulation factors and promote their activation, consistent with a procoagulant potential for EMP. In addition to PS exposure, EMP harbor tissue factor (TF), the initiator of the extrinsic coagulation pathway, suggesting that EMP could promote the assembly of clotting enzymes leading to thrombin generation. Besides their procoagulant activity, EMP also behave as a surface supporting plasmin generation by expressing the urokinase-type plasminogen activator (uPA) and its receptor (uPAR), which could counteract the thrombin generated by EMP. In this context, EMP supports a link between hemostasis and angiogenesis. Indeed, the plasminogen activation system plays a pivotal role in maintaining vascular patency and facilitating cell migration and angiogenesis. This proteolytic potential affects the angiogenic potential of endothelial progenitor cells. By conveying plasmin, EMP activate matrix metalloproteases (MMP) which are involved in the extracellular matrix degradation and the release of growth factors that play a crucial role in tissue remodeling, angiogenesis, and cancer spreading. Endothelial-, platelet-, and tumor-cell-derived MPs appear to be able to angiogenesis, an effect mediated by reactive oxygen species, metalloproteinases, growth factors such as vascular endothelial growth factor, or sphingomyelin. Apoptotic bodies from endothelial cells could also contribute to tissue repair mechanisms by stimulating the differentiation of progenitor cells. The polypeptide VEGF is a potent regulator of normal and abnormal angiogenesis. Chuang et al. in a comparative study investigated three groups of patients: group I include 23 hemodialysis (HD) patients with recurrent vascular access failure ( $<2$-year survival or synthetic arteriovenous graft $<1$ year survival), group II included $15 \mathrm{HD}$ patients with longer vascular access survival ( $>5$ year), and group III included 10 healthy volunteers as control. The expression of platelet activation markers (CD62P and fibrinogen receptor) and the numbers of platelet-derived MPs were measured. CD62P-positive platelets were significantly higher in group I than in groups II and III. Fibrinogen receptor-positive platelets were also significantly higher in group I than in group II and group III. A higher level of circulating activated platelets is associated with shorter survival of vascular access in HD patients [41]. Andro et al. in an experimental study investigated 29 healthy subjects, $46 \mathrm{HD}$ patients, 23 continuous ambulatory peritoneal dialysis (CAPD) patients, and 20 pre-dialyzed uremic patients. Analyses of platelet MPs were performed using a flow cytometer. Anexin V was used to probe procoagulant activity of PMPs. PMP counts at this study were significantly greater in each uremic groups than in controls. Platelet MP counts were significantly higher in uremic patients with thrombotic events than in those without thrombotic events. The HD procedure and existence of arteriovenous (AV) fistula did not affect PMP counts, but recombinant human erythropoietin (rHu EPO) treatment possibly enhanced the PMP release in these patients. Therefore, elevated PMP counts may trigger thrombosis in uremic patients [42].

\section{MP in immunity and inflammation}

It is now well established that MPs play a crucial role in inflammation. As a source of aminophospholipids and also a preferential substrate for phospholipase $A_{2}$, MPs are involved in the release of lysophosphatidic acid, which, in turn, triggers platelet aggregation and the inflammatory process. MPs are able to deliver arachidonic acid, leading to an increased expression of endothelial cyclooxygenase type 2. Cytokines also participate in the generation of MPs including PMPs with pro-inflammatory properties. It is documented that the released MPs contains interleukin-1, an important inflammatory factor. In addition, there is evidence showing that MPs shed by platelets can stimulate the production of pro-inflammatory cytokines such as IL-1, IL-6, IL-8, and TNF-a. These cytokines in turn activate inflammatory cells to generate more MPs, forming a positive feedback loop. MPs can also promote the expression of cell adhesion molecules in endothelial cells; MPs released by leukocytes have been demonstrated to contribute to the activated phenotype of rheumatoid arthritis synovial fibroblasts. MPs released by leukocytes may stimulate the expression of proangiogenic chemokines of CXCL1, CXCL2, CXCL3, CXCL5, CXCL6, and CXCL8. Taken together, MPs from certain cells may induce and intensify inflammatory response. This suggests that MPs can act as agonists of inflammation [5]. Neutrophil MPs are able to increase cytokine and chemokine release by endothelial cells by a nuclear factor-kB-independent pathway. Moreover, proteinase 3 (PR3) has been shown to be present on neutrophil MPs. Pro-inflammatory activities of PR3 include its ability to degrade matrix components, to enhance 
chemokine and tissue factor production by endothelial cells, and/or provoke endothelial cell apoptosis. The dissemination of highly adhesive MPs containing PR3 could thus greatly enhance inflammatory vascular lesions. On the contrary, neutrophil MPs could promote the resolution of inflammation, since they increase the release of transforming growth factor beta 1 by activated macrophages. Platelet MPs could participate to these modulations by adding new adhesion molecules to MPs aggregates (GPIIbIIIa, b1 integrins, GPIb, and P-selectin). Platelet MPs also contain bioactive lipids able to activate cyclooxygenase-2-dependent prostaglandin production in monocytes and endothelial cells. Finally, upon activation, platelets synthesize IL-1, which is released and processed on platelet MPs [43] (Fig. 4). In several studies, it has been shown that microparticles released by platelets, leukocytes, and endothelial cells can be found in conditions of endothelial dysfunction, acute and chronic vascular inflammation, and hypercoagulation. Endothelial microparticles can be found in several conditions that are associated with arterial hypertension. EMP are not only valuable surrogate markers reflecting the extent of endothelial dysfunction but additionally might promote the progression of arterial hypertension and its complications [44].

\section{MP in increasing cardiovascular disease}

MVs secreted from platelets play an important role in both coagulation and development of atherosclerosis. Increased levels of MVs derived from platelets can be found in patients with acute coronary syndrome, stroke, and peripheral arterial disease. Microparticles behave as effectors that play a deleterious role in renal diseases. They also represent novel biomarkers that are useful to appreciate cardiovascular risk associated with chronic kidney disease and sometimes disease activity [45]. In a prospective pilot study by Amabile et al., 81 stable hemodialyzed end-stage renal disease (ESRD) patients were enrolled. Platelet-free plasma obtained $72 \mathrm{~h}$ after last dialysis was analyzed by flow cytometry, and MPs with cellular origin are identified as endothelial, platelets, or erythrocyte. They concluded that increased plasma levels of EMP is a robust independent predictor of severe cardiovascular (CV) outcome in ESRD patients [46]. Moreover, the role of coagulation, thrombosis, platelet activation, and microparticles in the pathology

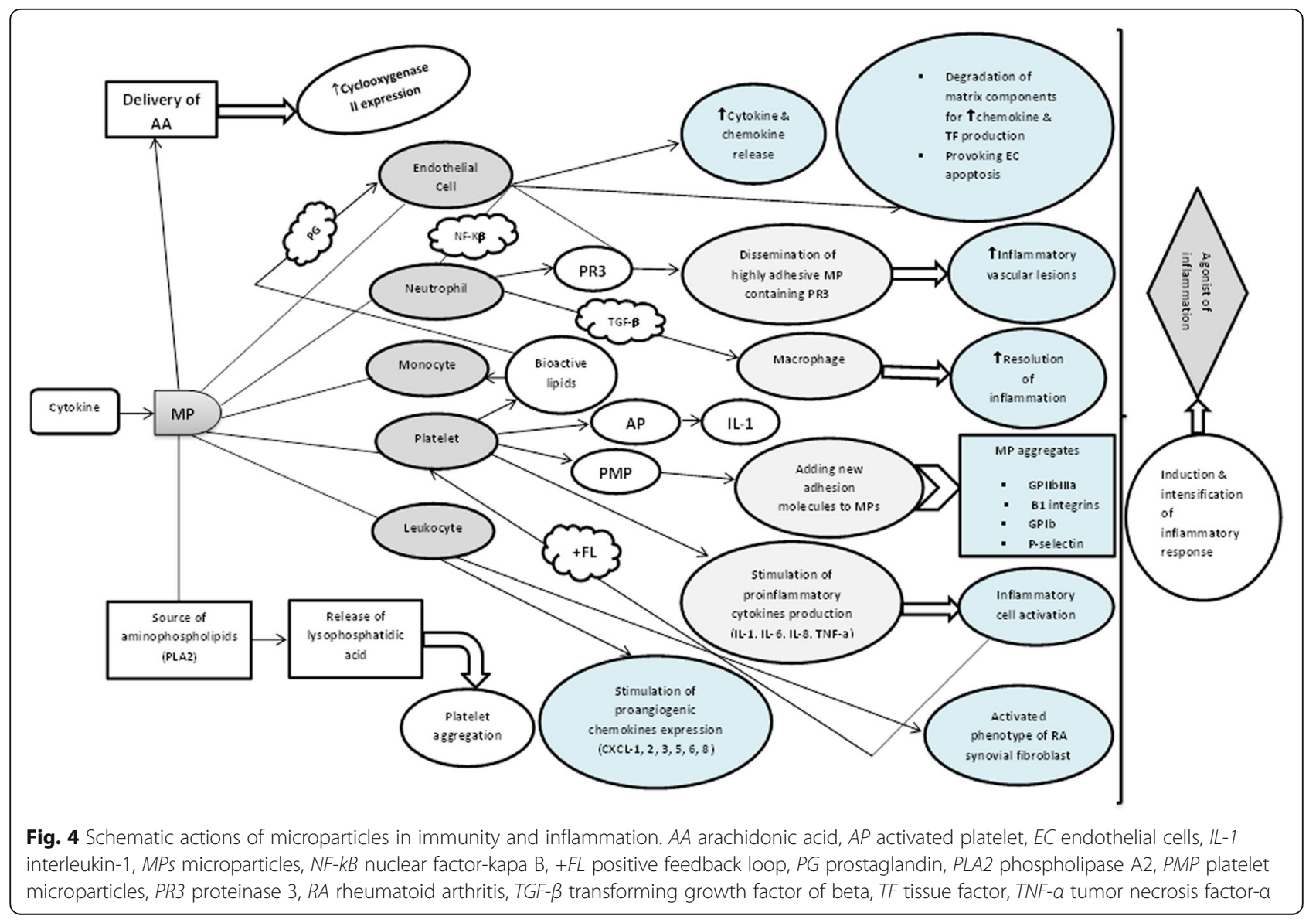


and progression of pulmonary arterial hypertension (PAH) is clearly characterized [47]. Endothelial microvesicles (eMVs) are considered to be markers of inflammation, endothelial injury, and endothelial dysfunction. As endothelial dysfunction is a well-known predictor of future cardiovascular diseases, endothelial MVs could be used to as biomarkers of vascular health. Similarly to eMVs in endothelial activation, platelet MVs (pMVs) are considered as platelet activation markers that contributes in cardiovascular diseases. pMVs possibly represent novel players in the network between inflammation and autoimmunity. Furthermore, circulating $\mathrm{CD} 31^{+} /$annexin $\mathrm{V}^{+}$apoptotic microparticles highly significantly predict the degree of endothelial dysfunction in humans with coronary artery disease [48]. Chronic renal failure patients are at high risk of cardiovascular events and display endothelial dysfunction, a critical element in the pathogenesis of atherosclerosis. Faure et al. in a crosssectional study evaluated 45 chronic renal failure patients, $30 \mathrm{HD}$ patients, and 36 healthy subjects. Circulating endothelial MPs were numerated by flow cytometry, and platelet MPs (CD41), leukocyte MPs (CD45) and annexin V MPs were also counted. CD144 EMP and CD146 EMP were significantly higher in chronic renal failure (CRF) and HD patients than in healthy subjects. Furthermore, annexin V MPs were elevated in both groups of uremic patients, and CD41PMPs and CD45 LMPs were increased in CRF and HD patients respectively. In vitro, para-cresol and indoxyl sulfate significantly increased both CD 146 and annexin-V EMP release. Increased levels of circulating EMP in CRF and HD patients represent a new marker of endothelial dysfunction in uremia [49].

\section{MP in apoptosis}

MPs derived from various origins, including monocytes, erythrocytes, endothelial cells, and platelets, have been reported to contain caspase 3. This process is believed to be a protective mechanism directed at removing proapoptotic machinery, since inhibition of MP-mediated caspase 3 release in endothelial cells is associated with increased apoptosis. It has been suggested that MPs may deliver caspase 3 to target cells, leading to the induction of apoptosis. However, as caspase 3 is involved in numerous cellular processes beyond cell death, the delivery of caspases may have an impact on several cellular processes [8].

Wang et al. in a prospective study investigated that starving stress endothelial progenitor MVs (sEPCs$\mathrm{MVs}$ ) and apoptotic stress endothelial progenitor MVs (aEPC-MVs) are functionally different on hypoxia/reoxygenation (H/R)-induced apoptosis and dysfunction. These functional roles might rely on the orchestrated mechanisms associated with MV-carried ribonucleic acids (RNAs) in control of reactive oxygen species (ROS) production and phosphatidylinositol-3 kinase/ endothelial nitric oxide synthase/nitric oxide (PI3K/ eNOS/NO) pathway in the target cells. These findings indicate that EPC-MVs could be used as a novel vehicle for treating $H / R$ injury [50].

\section{MP in oxidative stress}

MPs have been shown to regulate the production of reactive oxygen species (ROS). Interestingly, both the source of MPs and the manner in which they are formed appear to be a critical determinant of MPmediated pro-oxidative effects. Thus, the majority of studies suggest that MPs (endothelial-, monocyte-, and lymphocyte-derived) are capable of promoting oxidative stress in the endothelium through processes which may involve several enzymatic systems [8]. Fontaine et al. in a prospective study investigated blood plasmas of 24 patients on-pump and 10 off-pump before, $1 \mathrm{~h}$, and $24 \mathrm{~h}$ after cardiac surgery. Rings of rat thoracic aortas were incubated for $20 \mathrm{~h}$ with these different plasmas or saline. Then, superoxide anion production was assessed. Plasma isolated after on-pump, but not offpump coronary bypass surgery can induce superoxide generation by the vascular wall which seems related to circulating microparticles remaining present at least $24 \mathrm{~h}$ after the procedure that might be of endothelial origin [51]. In patients with CRF, one could speculate that the initial stimuli that lead to MP generation could result from a release of lipopolysaccharide (LPS), advanced glycation end-products (AGEs), pro-inflammatory cytokines [TNF $\alpha$ (tumor necrosis factor-a and interleukin-1 (IL-1)], or oxidized low density lipoprotein (LDL), reflecting the oxidant stress.

\section{Microparticles in kidney transplantation}

In addition to their diagnostic role as markers of kidney and vascular damage, these microparticles have various functions, e.g., intercellular communication, antiinflammation and anticoagulation, regulation of vascular tone, vascular wall permeability, and cell growth. MPs in kidney transplantation have dual effects, and, as such, some effects may cause pathologic conditions and sometimes they are considered as extracellular vesicles. For example, endothelial MPs may induce endothelial dysfunction, but at the same time, it has also been suggested that endothelial MPs are novel markers of endothelial dysfunction. Numerous studies indicate that MPs may trigger endothelial dysfunction by disrupting production of nitric oxide, promoting coagulation and inflammation, or altering angiogenesis and apoptosis (Fig. 5). MP are also implicated in the exchange of mRNA and proteins between cells. Circulating miRNAs are included into lipid or lipoprotein complexes such as 


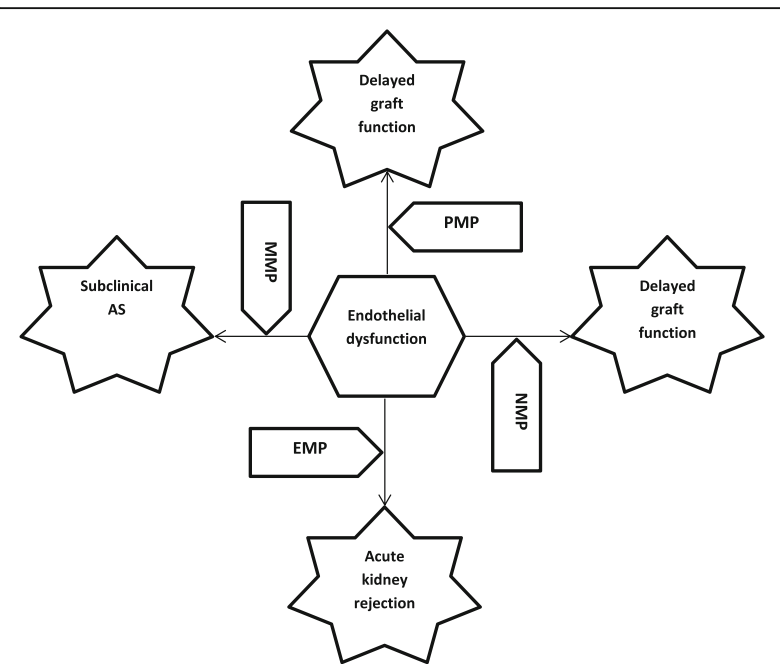

Fig. 5 Schematic diagram of endothelial dysfunction in kidney transplantation. Endothelial dysfunction causes vascular and inflammatory consequences through endothelial-, platelet-, monocyte-, and neutrophilic microparticles. EMP endothelial microparticles, MMP monocyte microparticles, MP microparticles, NMP neutrophil microparticles, PMP platelet microparticles, Subclinical AS subclinical atherosclerosis

microvesicles/microparticles or exosomes. Anglicheau et al. in a study investigated the miRNA profile in peripheral blood mononuclear cells (PBMCs) as well as kidney biopsies in patients with acute renal allograft rejection. These patients were shown to display a unique miRNA expression profile PBMCs and paired renal biopsy specimens. miRNAs overexpressed in renal biopsies (miR-142-5p, miR-155, and miR-223) followed the same pattern of expression in PBMCs, indicating that miRNA expression analysis might serve as a diagnostic test in this patient cohort [52]. Another study by Lorenzen et al. analyzed the miRNA expression profile in urine samples (quantitative real time PCR-based miRNA microarray) of patients with acute T cell-mediated renal allograft rejection. This approach was chosen to identify miRNAs deregulated in easily accessible urine to circumvent the potential risks associated with an invasive procedure such as kidney biopsy. Urine samples of patients were obtained at the time of biopsy. Patients with an acute rejection as diagnosed by a kidney biopsy showed reduced urinary levels of miR-210. In samples taken before and after the rejection period, miR-210 increased to levels of controls. In addition, a disease control group of transplant patients with urinary tract infection did not display altered miR210 levels. These results underline a potential specificity of urinary miR-210 for the diagnosis of acute $\mathrm{T}$ cellmediated rejection. Moreover, urinary miR-210 at the time of rejection predicted GFR decline at 1 year after transplantation [53]. Scian et al. in a prospective study investigated the identified miRNA signature in kidney transplant recipients. Total RNA was extracted from trizol from biopsy tissue or urinary cell fractions. Realtime quantitative-PCR were used for quantifying the expression of miR-142-3p, miR-32, miR-107, miR-204, and miR-211 in paired urine sample using pre-designed TaqMan $^{\circ}$ miRNA expression assays. They confirmed the differential expression of these five miRNAs. Differential expression was detected for miR-142-3p, miR-204, miR-107, miR-211, and miR-32. Furthermore, differential expression of miR-142-3p, miR-204, and miR-211 was also observed between patient groups in urine samples. A characteristic miRNA signature for interstitial fibrosis/ tubular atrophy (IF/TA) that correlates with paired urine samples was identified. These results support the potential use of miRNAs as noninvasive markers of IF/TA and for monitoring graft function [54].

VEGF is a mitogen for endothelial cells and is expressed widely by renal tissue and T cells. VEGF influences adhesion and migration of leukocytes across the endothelium. In a study, Shahbazi et al. investigated VEGF promoter polymorphisms by using sequencespecific primer-PCR in 173 renal transplant recipients. Acute rejection occurred in $38.7 \%$. VEGF in vitro expression was investigated in stimulated leukocytes from 30 controls. The VEGF-1154*G and VEGF-2578*C alleles were associated with higher VEGF production. VEGF-1154 GG and GA genotypes were significantly associated with acute rejection risk at 3 months. VEGF2578 CC and CA genotypes were associated with increased rejection risk. These data indicate that the VEGF-1154:G and VEGF-2578*C containing genotypes, encoding higher VEGF production, are strongly associated with acute rejection and may be useful markers of rejection risk [55]. A logical, but unstudied, extrapolation is that platelet-derived microparticles may also have an important function in transplant vasculopathy [56].

Ullal et al. in an experimental study investigated that particle binding to an antibody represents a useful serological assay to characterize autoantibody specificity as particles may represent an important antigenic form of deoxyribonucleic acid (DNA) that is exposed to the immune system in vivo. This DNA may have unique associations with other nuclear and cellular components on particles which may affect antigenicity as well as immunogenicity. Indeed, particles can display cytokines and serve as adjuvants. It is well known that the endothelium is the primary target of immunological attack in allograft rejection that could be detected early for effective patient care and management. Moreover, platelet microparticles suggest that they can migrate out of blood vessels by attaching to neutrophils thereby increasing their range of impact. 
Considering the fact that the platelet microparticles express p-selectin and CD-154, extravascular distribution of microparticles could influence the responses of graft infiltrating cells [57].

As certain miRNAs are characteristic for tumors, their presence within tumor-derived exosomes and microvesicles may serve novel biomarkers of cancer [58]. Thus, the genetic content of circulating microvesicles may be of great use for diagnostic and prognostic purposes after organ transplantation. MPs contain membrane proteins and cytosolic material derived from the cell from which they originate. The circulating EMP could be used as a marker of vascular endothelial cell damage and to determine asymptomatic patients who might be at higher risk of developing cardiovascular disease in CKD and renal transplant.

In a study by Jarmo et al., chronic renal allograft rejection is characterized by gradual progression suggesting persistent low-grade injury. Apoptotic cell death may be initiated by low-grade injury secondary to external factors, making apoptosis a potential pathway of chronic rejection. Protocol kidney biopsies of 20 pediatric renal allograft recipients (12 with chronic rejection and 8 with normal histology), 9 pediatric liver allograft recipients, and 7 children with minimal change nephrotic syndrome were evaluated. The presence of apoptotic cell death was studied by determining apoptosis-induced oligonucleosomal DNA fragmentation in the biopsy specimens. Significant DNA fragmentation was found only in the specimens from patients with chronic rejection. In situ investigation revealed increased apoptosis of both proximal and distal tubular epithelial cells, but not in the glomeruli or interstitium. The mean number of apoptotic tubular epithelial cells was higher in the renal allografts than in kidneys of liver transplant recipients or patients with minimal change nephrotic syndrome. These data provide biochemical evidence of increased apoptotic cell death of renal tubular epithelial cells in patients undergoing chronic renal allograft rejection [59].

Simmons et al. in a prospective cohort study timedependent changes in biomarkers of inflammation and oxidative stress before and after renal transplantation. Nineteen end-stage renal disease patients undergoing living-donor renal transplantation were enrolled. Pretransplant levels of the pro-inflammatory proteins IL-6, TNF- $\alpha$, and CRP, as well as the oxidative stress markers plasma protein carbonyls and F2-isoprostanes, were significantly elevated in ESRD patients compared with healthy control subjects. They observed rapid and significant declines in all of these biomarkers after transplantation that persisted for 2 months. These findings indicate that restoration of renal function by transplantation improves the chronic inflammation and increased oxidative stress associated with uremia, which may contribute to the improved survival afforded to ESRD patients by renal transplantation [60].

A recent study defined the safety and clinical feasibility of autologous mesenchymal stem cell transplantation in two human recipients of kidneys from living-related donors. It has been shown that infusion of MSCs after kidney transplantation is feasible and restricts $\mathrm{T}$ memory cell expansion while enlarging the $\mathrm{T}$ regulatory population, even if graft dysfunction is induced. One possible alternative to the MSC infusion in organ transplantation might be MV treatment [61].

Circulating MVs may have a great potential to detect possible immune rejections, and MV modulation may emerge as a therapeutic approach in organ rejection therapy $[62,63]$. Their actions in immunity, cardiovascular diseases, cancer, oxidative stress, blood coagulation, angiogenesis, apoptosis, rejection, and intercellular communication have been clearly demonstrated. Lactadherin, also known as milk fat globule-epidermal growth factor 8 (EGF-8), is a $45-\mathrm{kDa}$ glycoprotein secreted by macrophages. Lactadherin contains EGF-like domains at the amino terminus and two $\mathrm{C}$-domains at the carboxyl terminus that share homology to the phosphatidylserine-binding domains of blood coagulation factors V and VIII. Lactadherin binds to apoptotic cells, activated platelets, and phosphatidylserine expressing red blood cells via the $\mathrm{C}$-domains and anchors them to macrophage integrins via its RGD sequence in the EGF domain. Dasgupta et al. examined the role of lactadherin in the clearance of phosphotidylserine-rich platelet-derived microvesicles. Investigators demonstrated that a defective clearance of platelet-derived MV can induce a hypercoagulable state [64]. Furthermore, investigations showed that attenuated platelet MV formation may be a sign of former activation of platelets that could influence graft function and survival. On the other hand, binding of PMP to cells can modify cell functional properties. For example, it has been elegantly demonstrated that PMP can bind hematopoietic progenitors and stimulate their engraftment [65]. An early decrease of circulating microparticle levels and procoagulant activity is observed after renal transplantation and persists during the 1 year of follow-up. Therefore, researchers suggest that MP could be associated to improvement of vascular dysfunction reported after transplant. Furthermore, endothelial dysfunction occurs in hemodialysis and kidney-transplanted patients and can be enhanced by immunosuppressive therapy. Circulating endothelial cells (CEC), endothelial microparticles (EMP), and soluble vascular cell adhesion molecule-1 (sVCAM-1) provide information on endothelium activation and damage. In study by Al-massarani et al., the impact of two immunosuppressive regimens [Cyclosporine A/ Azathioprine vs. Tacrolimus/Mycophenolate Mofetil 
(CsA/Aza vs. Tac/MMF)] on the kinetics of CEC, EMP, and sVCAM-1 levels in 52 patients, both before graft and 3, 6, 9 and 12 months after graft, was evaluated. They reported the beneficial impact of renal transplantation on endothelial injury through circulating levels of endothelial markers and concluded that these effects are more pronounced in patients treated by CsA/Aza and are impaired in relation with cytomegalovirus (CMV) and cardiovascular diseases. These results are suggestive of the noninvasive endothelial evaluation as an early index of vascular injury [66].

Patients with chronic renal failure suffer from dysfunction in coagulation. Kidney transplantation induces inflammatory reactions and thus activation of platelets. Activated platelets, in turn, form microvesicles by shedding. These microvesicles have been shown to have coagulant activities. Activated platelets in prolonged cold ischemia were associated with delayed graft function and inferior survival. They concluded decreased platelet microvesicle formation after ex vivo stimulation with tartrate-resistant acid phosphatase (TRAP) was associated with longer graft ischemia time. This may be a sign of former activation of platelets which could influence graft function and survival (Table 2). Although it has been known that platelets modify vascular inflammation by secretion of soluble mediators and release of microparticles, new aspects of these mechanisms are being defined. New findings also demonstrate heterologous interactions of platelet microparticles with leukocytes that may increase their range of impact. By attaching to neutrophils, platelet microparticles appear to migrate out of blood vessels and into other compartments where they stimulate secretion of cytokines. Contact of platelets with extracellular matrix also can result in cleavage of hyaluronan into fragments that serve as an endogenous danger signal. Considering the fact that platelet microparticles express p-selectin and CD154, extravascular distribution of microparticles could influence the responses of graft-infiltrating cells [67]. Contrastly, Trappenburg et al., in a cross-sectional study, investigated blood samples of 27 patients with chronic kidney disease (8 CKD stage 4, 9 peritoneal disease, 10 hemodialysis patients) and 10 controls before and after hemodialysis. Degree and nature of endothelial activation were measured by von Willebrand factor (vWF) and vWF propeptide levels. Cellular MPs were characterized by flow cytometry, and MP-specific thrombin generation (TG) measurements showed renal failure is accompanied by endothelial activation of a different nature in CKD4 and peritoneal dialysis (PD) patients compared to hemodialysis (HD) patients, and results in all subgroups in an increase of mainly platelet-derived MPs that appear to be less procoagulant than in other disease states, possibly because of the uremic functional defect of their cellular source [68]. In organ transplantation, blood-borne cells and macromolecules (e.g., antibodies) of the host immune system are brought into direct contact with the endothelial cell (EC) lining of graft vessels. In this location, graft ECs play several roles in allograft rejection, including the initiation of rejection responses by presentation of alloantigen to circulating $\mathrm{T}$ cells, the development of inflammation and thrombosis, and as targets of injury and agents of repair [69]. The use of urinary extracellular vesicles (EVs) as a source of biomarkers for kidney injury after renal transplantation (RTx) was probed by Alvarez et al. In this study, the authors demonstrated the presence of neutrophil gelatinase-associated lipocalin (NGAL) in cellular fraction and in urinary EVs from patients. Urinary EVs NGAL detection differed between patients and controls. Interestingly, different quantities of NGAL were detected between deceased and living donors. Thus, various studies suggest that NGAL could be a biomarker of damage and delayed graft function [70, 71].

Concerning kidney function, experiments revealed that the beneficial effect of MSCs on recovery from acute kidney injury is in part mediated via MVs. MV function in this setting was CD-44 and beta- 1 integrin dependent. Because miRNAs treatment of MSC-derived MVs abolished the beneficial effects, the authors concluded that this effect is most likely mediated via horizontal gene transfer [72]. MPs contain membrane proteins and cytosolic material that are derived from their original cells. EMP having CD144, CD 146, CD31+/CD41-, CD51, and CD105 may be used to evaluate the vascular endothelial cell damage and determine asymptomatic patients who might be at higher risk of developing cardiovascular disease in CKD and renal transplantation [73]. Urinary extracellular vesicles contain proteins from all sections of the nephron, whereas the most of studied circulating extracellular vesicles are derived from platelets, immune cells, and the endothelium. In addition to their diagnostic role as markers of kidney and vascular damage, extracellular vesicles may have functional significance in renal health and disease by facilitating communication between cells and protecting against kidney injury and bacterial infection in the urinary tract. It is crucial that researchers provide detailed information about their methodology and use several techniques to ensure that the particles that they are studying are truly EVs and not non-EV components, such as lipids or protein complexes. In addition, a standard and uniform language should be used among all scientific communications [74].

\section{Conclusions}

Elevated levels of MP have been detected throughout the entire process of vascular damage associated with 


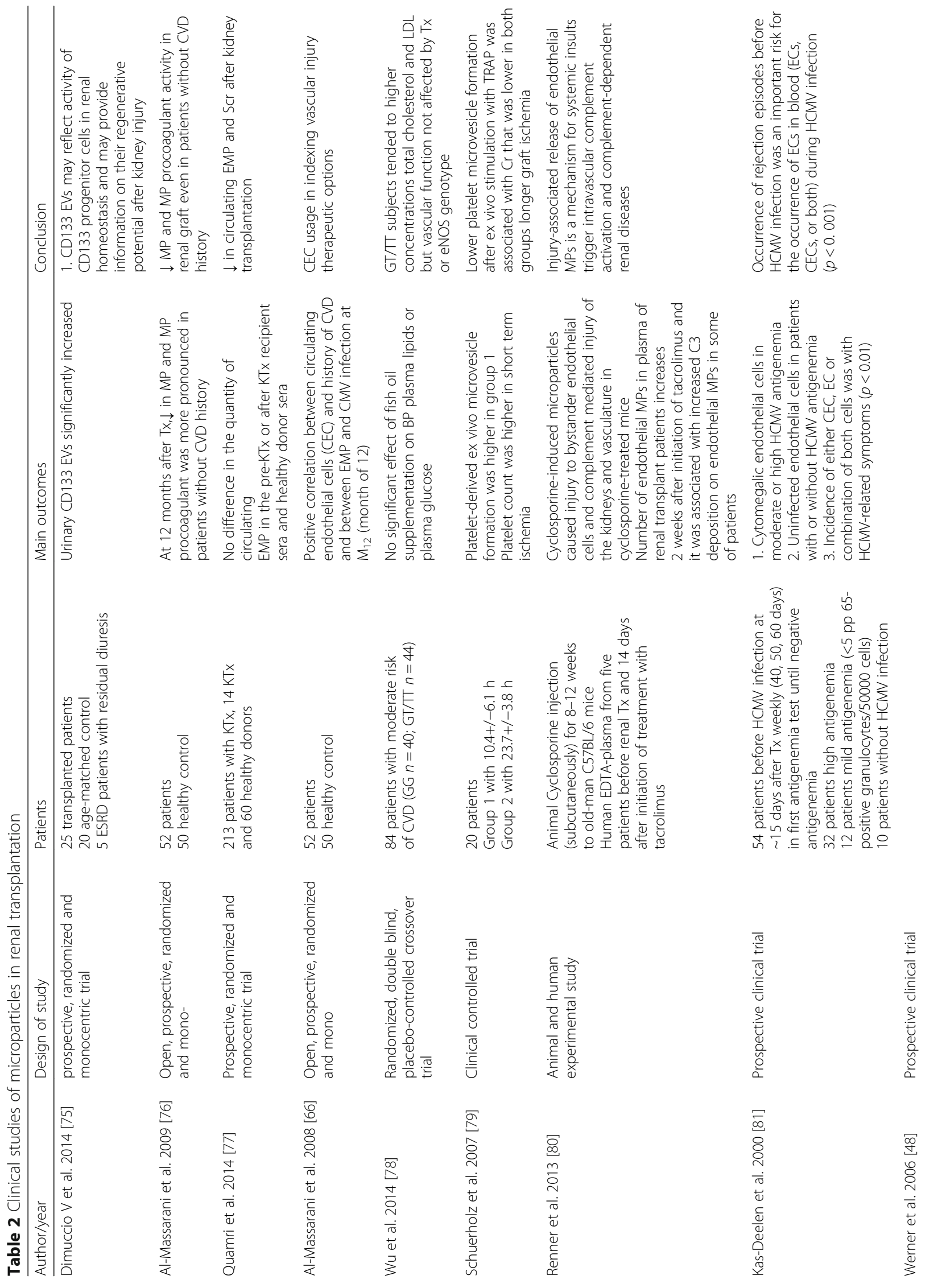




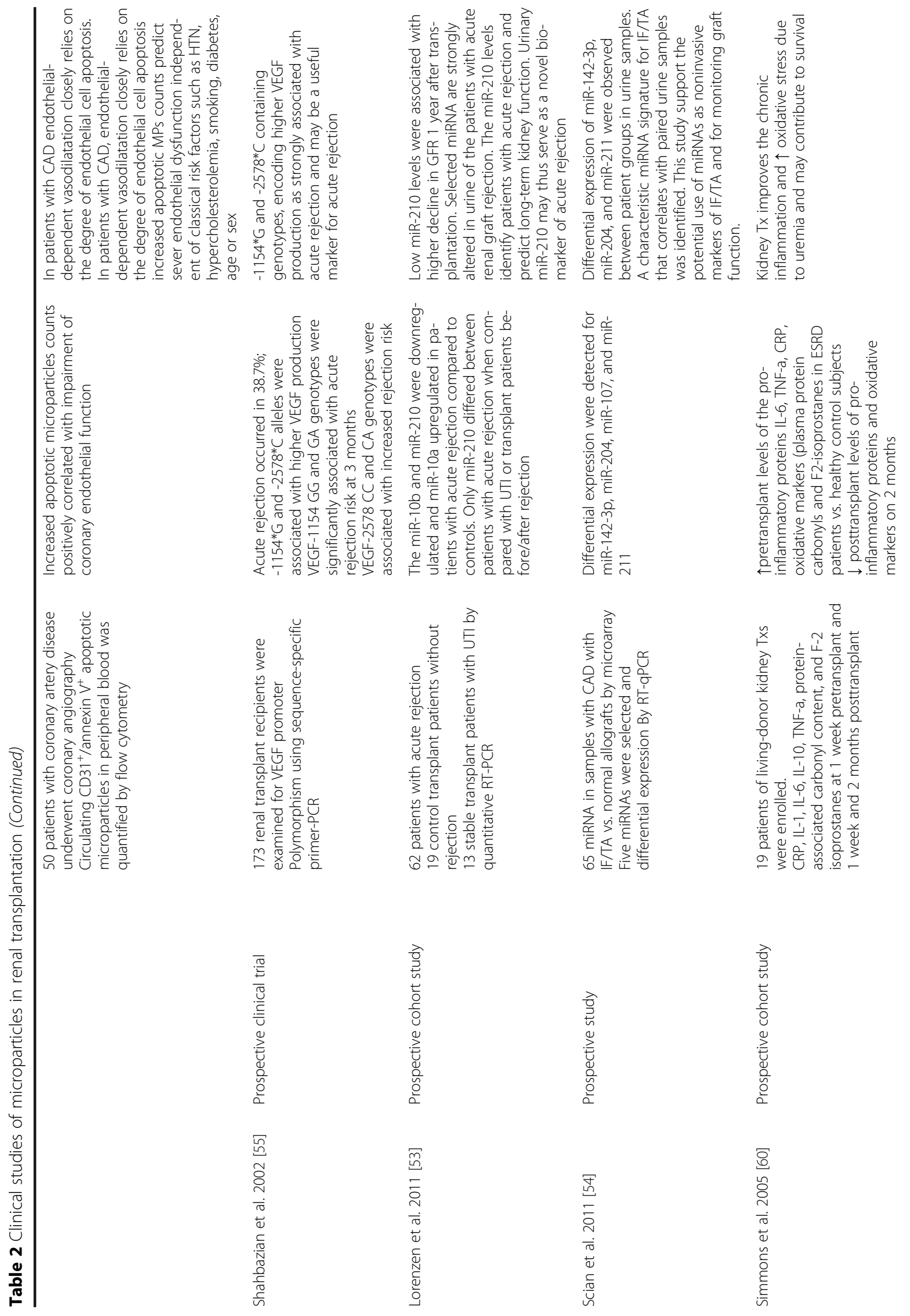




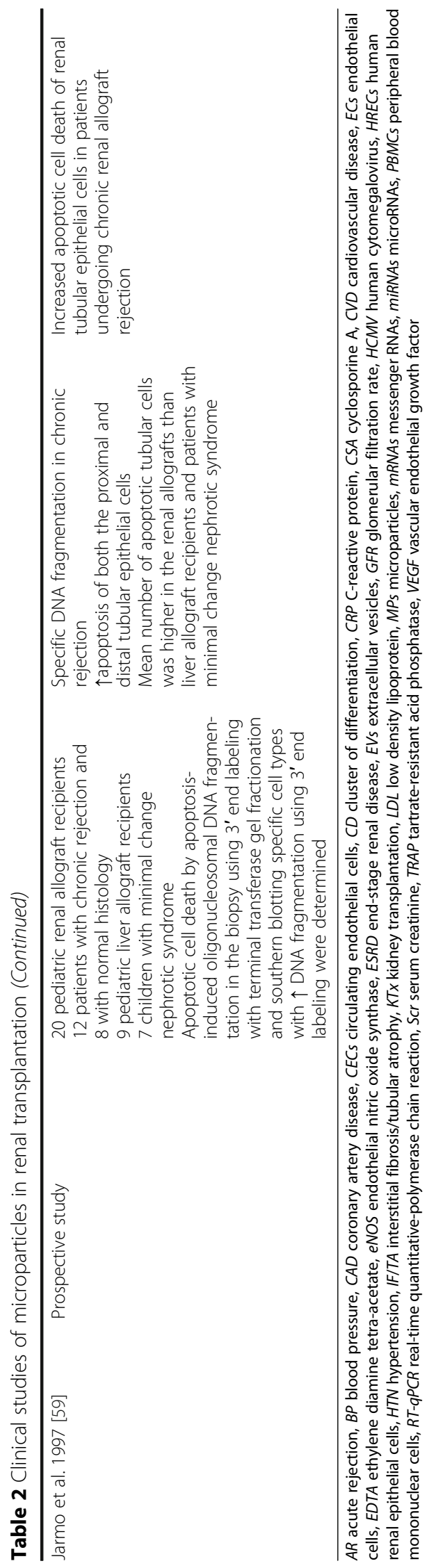


renal diseases. Furthermore, MPs are key actors in cardiovascular diseases that are associated with renal diseases and are elevated in patients with hemodialysis. Furthermore, it recently has demonstrated that higher levels of endothelial MPs observed in hemodialyzed patients reach to normal values after graft. Circulating microvesicles may have a great potential to detect possible immune rejections, and microvesicle modulation may emerge as a therapeutic approach in organ rejection therapy. Because we are unaware from the other functional roles of microparticles, more key and original studies which be cost-effective are necessary to characterize functional roles of microparticles in renal diseases and clinical research.

\section{Acknowledgements}

None.

\section{Funding}

Not applicable.

Availability of data and materials

Not applicable.

\section{Competing interests}

The author declares that she has no competing interests.

\section{Consent for publication}

Not applicable.

Ethics approval and consent to participate

Not applicable.

\section{Publisher's Note}

Springer Nature remains neutral with regard to jurisdictional claims in published maps and institutional affiliations.

Received: 16 December 2016 Accepted: 2 March 2017

Published online: 23 June 2017

\section{References}

1. Fang YD, King WH, Li YJ, Gleadle MJ. Exosomes and the kidney: blaming the messenger. Nephrology. 2013;18:1-10.

2. Lovren F, Verma S. Evolving role of microparticles in the pathophysiology of endothelial dysfunction. Clin Chem. 2013;59:1166-74

3. Van der Pol E, Böing AN, Harrison P, Sturk A, Nieuwland R. Classification, functions, and clinical relevance of extracellular vesicles. Pharmacol Rev. 2012;64:676-705.

4. Mackman N. On the trail of microparticles. Circ Res. 2009;104:925-7.

5. ZH W, CL J, Li H, Qiu GX, Gao CJ, Weng XS. Membrane microparticles and diseases. Eur Rev Med Pharmacol Sci. 2013; 17:2420-7.

6. Rubin O, Canellini G, Delobel J, Lion N, Tissot JD. Red blood cell microparticles: clinical relevance. Transfus Med Hemother. 2012:39:342-7.

7. Shet AS. Characterizing blood microparticles: technical aspects and challenges. Vasc Health Risk Manag. 2008:4:769-74.

8. Burger D, Schock S, Thombson SC, Montezano CA, Hakim MA, Touyz MR. Microparticles:biomarkers and beyond. Clin Sci. 2013;124:423-41.

9. Hugel B, Martinez MC, Kunzelmann C, Freyssinet JM. Membrane microparticles: two sides of the coin. Physiology. 2005;20:22-7.

10. Barteneva NS, Fasler-Kan E, Bernimoulin M, Stern JN, Ponomarev ED, Duckett $L$, et al. Circulating microparticles: square the circle. BMC Cell Biol. 2013;14:1-21.

11. Morel O, Jesel L, Freyssinet JM, Toti F. Cellular mechanisms underlying the formation of circulating microparticles. Arterioscler Thromb Vasc Biol. 2011; 31:15-26.
12. Dignat-George $F$, Boulanger $C M$. The many faces of endothelial microparticles. Arterioscler Thromb Vasc Biol. 2011;31:27-33.

13. Sadallah S, Eken C, Schifferli JA. Ectosomes as modulators of inflammation and immunity. Clin Exp Immunol. 2010;163:26-32.

14. Puddu P, Puddu GM, Cravero E, Muscari S, Muscari A. The involvement of circulating microparticles in inflammation, coagulation and cardiovascular diseases. Can J Cardiol. 2010;26:140-5.

15. Boulanger CM, Amabile N, Tedgui A. Circulating microparticles: a potential prognostic marker for atherosclerotic vascular disease. Hypertension. 2006; 48:180-6.

16. Distler JH, Huber LC, Hueber AJ, Reich 3rd CF, Gay S, Distler O, et al. The release of microparticles by apoptotic cells and their effects on macrophages. Apoptosis. 2005;10:731-41.

17. Herring JM, McMichael MA, Smith SA. Microparticles in health and disease Vet Intern Med. 2013:27:1020-33.

18. Nomura S, Ozaki Y, Ikeda Y. Function and role of microparticles in various clinical settings. Thromb Res. 2008;123:8-23.

19. Mesri M, Altieri DC. Endothelial cell activation by leukocyte microparticles. J Immunol. 1998;161:4382-7.

20. Zwaal RF, Comfurius P, Bevers EM. Surface exposure of phosphatidylserine in pathological cells. Cell Mol Life Sci. 2005:62:971-88.

21. Litvack ML, Post M, Palaniyar N. IgM promotes the clearance of small particles and apoptotic microparticles by macrophages. PLoS One. 2011;6: 17223.

22. Morel O, Toti F, Hugel B, Bakouboula B, Camoin-Jau L, Dignat-George F, et al. Procoagulant microparticles disrupting the vascular homeostasis equation? Arterioscler Thromb Vasc Biol. 2006;26:2594-604.

23. Burton JO, Hamali HA, Singh R, Abbasian N, Parsons R, Patel AK, et al. Elevated levels of procoagulant plasma microvesicles in dialysis patients. PLoS One. 2013:8:72663.

24. Burger D, Thibodeau JF, Holterman CE, Burns KD, Touyz RM, Kennedy CR, et al. Urinary podocyte microparticles identify prealbuminuric diabetic glomerular injury. J Am Soc Nephrol. 2014;25:1401-7.

25. Santucci L, Bruschi M, Candiano G, Lugani F, Petretto A, Bonanni A, et al. Urine proteome biomarkers in kidney diseases. I. Limits, perspectives, and first focus on normal urine. Biomark Insights. 2016;11:41-8.

26. Lorenzen JM, Thum T. Circulating and urinary microRNAs in kidney disease. Clin J Am Soc Nephrol. 2012:7:1528-33.

27. Salih M, Zietse R, Hoorn EJ. Urinary extracellular vesicles and the kidney: biomarkers and beyond. Am J Physiol Renal Physiol. 2014;306:1251-9.

28. Aatonen MT, Ohman T, Nyman TA, Laitinen S, Gronholm M, Siljander PR. Isolation and characterization of platelet-derived extracellular vesicles. J Extracell Vesicles. 2014:3:1-15.

29. Nolan S, Dixon R, Norman K, Hellewell P, Ridger V. Nitric oxide regulates neutrophil migration through microparticle formation. Am J Pathol. 2008; 172:265-73.

30. Mutschler DK, Larsson AO, Basu S, Nordgren A, Eriksson MB. Effects of mechanical ventilation on platelet microparticles in bronchoalveolar lavage fluid. Thromb Res. 2002;108:215-20.

31. Porro C, Lepore S, Trotta T, Castellani S, Ratclif L, Battaglino A, et al. Isolation and characterization of microparticles in sputum from cystic fibrosis patients. Respir Res. 2010;11:94

32. Berckmans RJ, Nieuwland R, Tak PP, Böing AN, Romijn FP, Kraan MC, et al. Cell-derived microparticles in synovial fluid from inflamed arthritic joints support coagulation exclusively via a factor VII-dependent mechanism. Arthritis Rheum. 2012;46:2857-66.

33. Press JZ, Reyes M, Pitteri SJ, Pennil C, Garcia R, Goff BA, et al. Microparticles from ovarian carcinomas are shed into ascites and promote cell migration. Int J Gynecol Cancer. 2012;22:546-2.

34. Berckmans RJ, Sturk A, van Tienen LM, Schaap MC, Nieuwland R. Cell-derived vesicles exposing coagulant tissue factor in saliva. Blood. 2011;117:3172-73.

35. Hoyer FF, Nickenig G, Werner N. Microparticles—-messengers of biological information. J Cell Mol Med. 2010;14:2250-6.

36. Diehl P, Fricke A, Sander L, Stamm J, Bassler N, Htun N, et al. Microparticles: major transport vehicles for distinct microRNAs in circulation. Cardiovasc Res. 2012;93:633-44.

37. Bitzer M, Ben-Dove IZ, Thum T. Microparticles and microRNAs of endothelial progenitor cells ameliorate acute kidney injury. Kidney Int. 2012:82:377-5.

38. Fritzsching B, Schwer B, Kartenbeck J, Pedal A, Horejsi V, Ott M. Release and intercellular transfer of cell surface CD81 via microparticles. Immunol. 2002; 169:5531-7. 
39. Zwicker JI, Trenor III CC, Furie BC, Furie B. Tissue factor-bearing microparticles and thrombus formation. Arterioscler Thromb Vasc Biol. 2011; 31:728-33.

40. Shai $E$, Varon D. Development, cell differentiation, angiogenesis-microparticles and their roles in angiogenesis. Arterioscler Thromb Vasc Biol. 2011;31:10-4.

41. Chuang YC, Chen JB, Yang LC, Kuo CY. Significance of platelet activation in vascular access survival of haemodialysis patients. Nephrol Dial Transplant. 2003;18:947-54.

42. Ando M, Iwata A, Ozeki Y, Tsuchiya K, Akiba T, Nihei H. circulating plateletderived microparticles with procoagulant activity may be a potential cause of thrombosis in uremic patients. Kidney Int. 2002;62:1757-63.

43. Daniel L, Fakhouri F, Joly D, Lesavre P, Mecarelli-Halbwalchs L, DignatGeorge F, et al. Increase of circulating neutrophil and platelet microparticles during acute vasculitis and hemodialysis. Kidney Int. 2006;69:1416-23.

44. Helbing T, Olivier C, Bode C, Moser M, Diehl P. Role of microparticles in endothelial dysfunction and arterial hypertension. World J Cardiol. 2014;6: 1135-39.

45. Daniel L, Die L, Berland Y, Lesavre P, Mecarelli-Halbwalchs L, Dignat-George F. Circulating microparticles in renal diseases. Nephrol Dial Transplant. 2008; 23:2129-32

46. Amabile N, Guerin AP, Tedgui A, Boulanger CM, London GM. Predictive value of circulating endothelial microparticles for cardiovascular mortality in endstage renal failure: a pilot study. Nephrol Dial Transplant. 2012;27:1873-80.

47. Lannan KL, Phipp RP, White RJ. Thrombosis, platelets, microparticles, and PAH: more than clot. Drug Discov Today. 2014;19:1230-5.

48. Werner N, Wassmann S, Ahlers P, Kosiol S, Nickenig G. Circulating CD31 ${ }^{+}$/annexin $\mathrm{V}^{+}$apoptotic microparticles correlate with coronary endothelial function in patients with coronary artery disease. Arterioscler Thromb Vasc Biol. 2006;26:112-6.

49. Faure $V$, Dou L, Sabatier F, Cerini C, Sampol J, Berland Y, Brunet P, DignatGeorge F. Elevation of circulating endothelial microparticles in patients with chronic renal failure. J Thromb Haemost. 2006:4:566-73.

50. Wang J, Chen S, Ma X, Cheng C, Xiao X, Chen J, et al. Effects of endothelial progenitor cell-derived microvesicles on hypoxia/reoxygenation-induced endothelial dysfunction and apoptosis. Oxid Med Cell Longev. 2013;2013:572729.

51. Fontaine D, Pradier O, Haqcuabard M, Stefanidis C, Carpentier Y, de Canniere $D$, et al. Oxidative stress induced by circulating microparticles in on-pump but not in off-pump coronary surgery. Acta Cardiol. 2009:64:715-22.

52. Anglicheau D, Sharma VK, Ding R, Stamm J, Bassler N, Htun N, et al. MicroRNA expression profiles predictive of human renal allograft status. Proc Natl Acad Sci U S A. 2009;106:5330-35.

53. Lorenzen JM, Volkmann I, Fiedler J, et al. Urinary miR-210 as a mediator of acute T-cell mediated rejection in renal allograft recipients. Am J Transplant 2011;11:2221-7.

54. Scian MJ, Maluf DG, David KG, Archer KJ, Suh JL, Wolen AR, et al. MicroRNA profiles in allograft tissues and paired urines associate with chronic allograft dysfunction with IF/TA. Am J Transplant. 2011;11:2110-22.

55. Shahbazian M, Fryer AA, Pravica V, Brogan IJ, Ramsay HM, Hutchinson IV, et al. Vascular endothelial growth factor gene polymorphisms are associated with acute renal allograft rejection. J Am Soc Nephrol. 2002;13:260-4.

56. Morrell CN, Sun H, Swaim AM, Baldwin III WM. Platelets an inflammatory force in transplantation. Am J Transplant. 2007;7:2447-54

57. Ullal AJ, Marion TN, Pisetsky DS. The role of antigen specificity in the binding of murine monoclonal anti-DNA antibodies to microparticles from apoptotic cells. Clin Immunol. 2014:154:178-87.

58. Gyorgy B, Szabo TG, Pasztoi M, Pál Z, Misják P, Aradi B, et al. Membrane vesicles, current state-of-the-art: emerging role of extracellular vesicles. Cell Mol Life Sci. 2011;68:2667-88.

59. Jarmo L, Pauliina E, Christer H, Leo D. Apoptotic cell death in human chronic renal renal allograft rejection. Transplantation. 1997;63:101-5.

60. Simmons EM, Langone A, Sezer MT, Vella JP, Recupero J, Morrow JD, et al. Effect of renal transplantation on biomarkers of inflammation and oxidative stress in end-stage renal disease patients. Transplantation. 2005;79:914-9.

61. Tetta C, Bruno S, Fonsato V, Deregibus MC, Camussi G. The role of microvesicles in tissue repair. Organogenesis. 2011;7:105-15

62. Fleissner F, Goerzig Y, Haverich A, Thum T. Microvesicles as novel biomarkers and therapeutic targets in transplantation medicine. Am J Transplant. 2012;12:289-97.

63. Cui J, Yang J, Cao W, Sun Y. Differential diagnosis of acute rejection and chronic cyclosporine nephropathy after rat renal transplantation by detection of endothelial microparticles (EMP). Med Hypotheses. 2010;75:666-8.
64. Dasgupta SK, Abdel-Monem H, Niravath P, Le A, Bellera RV, Langlois K, et al. Lactadherin and clearance of platelet-derived microvesicles. Blood. 2009;113: 1332-9.

65. Janowska-Wieczorek A, Majka M, Kijowski J, Baj-Krzyworzeka M, Reca R, Turner AR, et al. Platelet-derived microparticles bind to hematopoietic stem/ progenitor cells and enhance their engraftment. Blood. 2001;98:3143-9.

66. Al-Massarani G, Vacher-Coponat H, Paul P, Widemann A, Arnaud L, Loundou A, et al. Impact of immunosuppressive treatment on endothelial biomarkers after kidney transplantation. Am J Transplant. 2008:8:2360-67.

67. Baldwin III WM, Kuo HH, Morrell CN. Platelets: versatile modifiers of innate and adaptive immune responses to transplants. Curr Opin Organ Transplant. 2011; 16:41-6

68. Trappenburg MC, Van Schilfgaarde M, Frerichs FC, Spronk HM, ten Cate H, de Fijter CW, et al. Chronic renal failure is accompanied by endothelial activation and a large increase in microparticle numbers with reduced procoagulant capacity. Nephrol Dial Transplant. 2012;27:1446-53.

69. Al-Lamki RS, Bradley JR, Pober JS. Endothelial cells in allograft rejection. Transplantation. 2008:86:1340-48

70. Alvarez S, Suazo C, Boltansky A, Ursu M, Carvajal D, Innocenti G, et al. Urinary exosomes as a source of kidney dysfunction biomarker in renal transplantation. Transplant Proc. 2013;45:3719-23.

71. Gamez-valero A, Lozano-Ramos SI, Bancu I, Lauzurica-Valdemoros R, Borràs FE. Urinary extracellular vesicles as source of biomarkers in kidney diseases. Front Immunol. 2015:6:6.

72. Bruno S, Grange C, Deregibus MC, Calogero RA, Saviozzi S, Collino F, et al. Mesenchymal stem cell derived microvesicles protect against acute tubular injury. J Am Soc Nephrol. 2009;20:1053-67.

73. Dursun I, Yel S, Unsur E. Dynamics of circulating microparticles in chronic kidney disease and transplantation: is it really reliable marker? World J Transplant. 2015;5:267-75.

74. Erdbrugger U, Le TH. Extracellular vesicles in renal diseases: more than nove biomarkers? J Am Soc Nephrol. 2016;27:12-26.

75. Dimuccio V, Ranghino A, Barbato LP, et al. Urinary CD133+ extracellular vesicles are decreased in kidney transplanted patients with slow graft function and vascular damage. PLoS One. 2014;9:104490.

76. Al-Massarani G, Vacher-Coponat H, Paul P, Arnaud L, Loundou A, Robert S, et al. Kidney transplantation decreases the level and procoagulant activity of circulating microparticles. Am J Transplant. 2009;9:550-7.

77. Quamri Z, Pelletier R, Foster J, Kumar S, Momani H, Ware K, et al. Early posttransplant changes in circulating endothelial microparticles in patients with kidney transplantation. Transplant Immunol. 2014;3:60-4.

78. Wu SY, Mayneris-Perxachs J, Lovegrove JA, Todd S, Yaqoob P. Fish-oil supplementation alters numbers of circulating endothelial progenitor cells and microparticles independently of eNOS genotype. Am J Clin Nutr. 2014; 100:1232-43.

79. Schuerholz T, Weissig A, Juettner B, Becker T, Scheinichen D. Ex vivo microvesicle formation after prolonged ischemia in renal transplantation. Thromb Res. 2007:120:231-6.

80. Renner B, Klawitter J, Goldberg R, McCullough JW, Ferreira VP, Cooper JE, et al. Cyclosporine induces endothelial cell release of complementactivating microparticles. J Am Soc Nephrol. 2013;24:1849-62.

81. Kas-Deelen AM, De Maar EF, Harmsen MC, Driessen C, Van Son WJ, The TH, et al. Uninfected and cytomegalic endothelial cells in blood during cytomegalovirus infection: effect of acute rejection. J Infect Dis. 2000;181:721-4.

\section{Submit your next manuscript to BioMed Central and we will help you at every step:}

- We accept pre-submission inquiries

- Our selector tool helps you to find the most relevant journal

- We provide round the clock customer support

- Convenient online submission

- Thorough peer review

- Inclusion in PubMed and all major indexing services

- Maximum visibility for your research

Submit your manuscript at www.biomedcentral.com/submit 